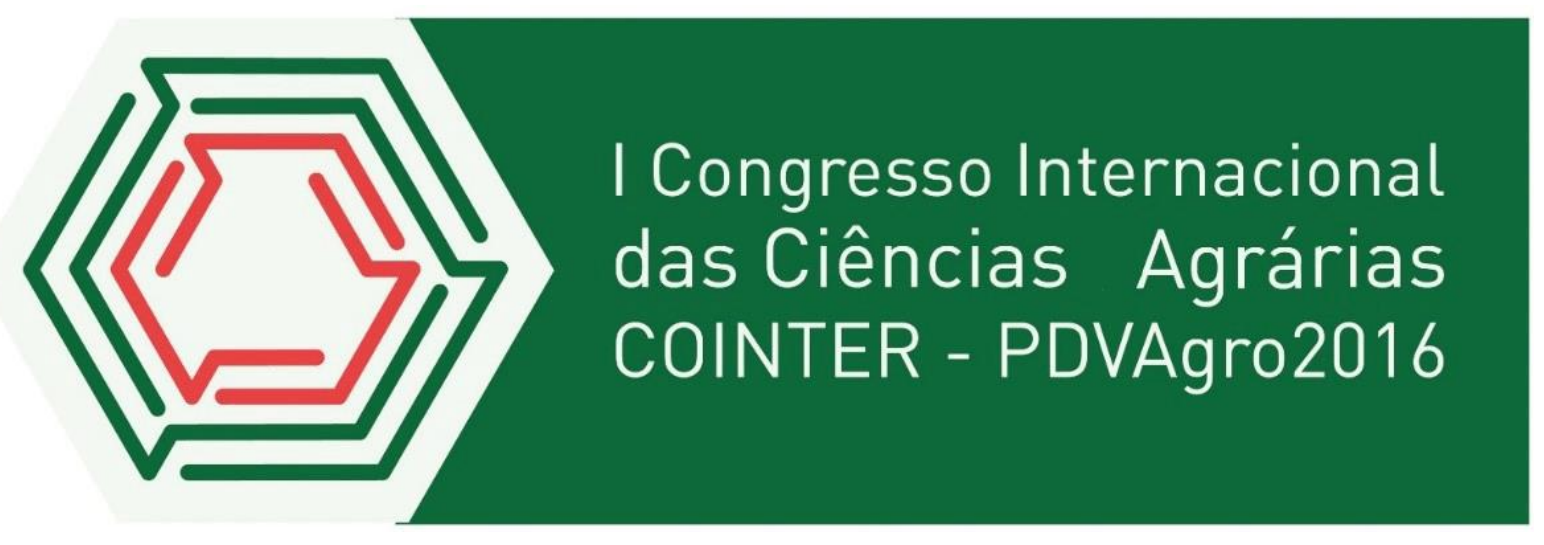

\title{
A MATÉRIA ORGÂNICA E SUA INFLUÊNCIA NAS FRAÇÕES GRANULOMETRICAS DO SOLO E NOS LIMITES DE ATTERBERG
}

\author{
Apresentação: Comunicação Oral \\ Mário José Ribeiro da Silva ${ }^{1}$; Josineide Braz de Miranda ${ }^{2}$
}

\section{Resumo}

Determinar as características do solo é bastante importante de acordo com os diferentes usos a que será destinado este solo (agricultura ou construção). A análise granulométrica, o teor de matéria orgânica do solo e os limites de liquidez e plasticidade são ferramentas importantes nessa caracterização. O objetivo deste trabalho foi avaliar a influência da matéria orgânica (MO) nos valores do limite de liquidez (LL) e plasticidade (LP) do solo, e na distribuição das frações granulométricas do mesmo, a partir de uma análise comparativa entre dois métodos de determinação da matéria orgânica. Para tanto, amostras de dois solos (SJ e SB) foram coletadas em pontos distintos do município de Pesqueira-PE. A determinação do teor de MO foi realizada segundo dois procedimentos: Perda de Massa por Ignição e Oxidação através da reação com $\mathrm{H}_{2} \mathrm{O}_{2}$ a $30 \%$. A determinação granulométrica realizou-se através de peneiramento seco e pipetagem. Para o ensaio de LL utilizou-se o aparelho de Casagrande, e para o ensaio de LP fez-se rolar sobre um vidro esmerilhado uma alíquota do solo até se transformar num cilindro. Constatou-se que os teores de MO nos solos oxidados com $\mathrm{H}_{2} \mathrm{O}_{2}$ foram significativamente maiores do que nos solos calcinados. $\mathrm{O}$ que sugere que o $\mathrm{H}_{2} \mathrm{O}_{2}$ oxidou também a $\mathrm{MO}$ refratária, mais resistente à degradação. $\mathrm{O}$ teor de MO no solo SJ peneirado foi maior que no SJ natural, confirmando que a matéria orgânica tem preferência de adsorção pelas frações granulométricas mais finas. As frações granulométricas grosseiras $(>0,063 \mathrm{~mm})$ se distribuíram de forma semelhante, indicando que a MO não influência a distribuição dos grãos nas diferentes frações grosseiras. Constatou-se uma diferença para os dois solos, na distribuição das frações finas entre o controle (com MO)

1 Mestre em Geotecnia, IFPE Campus Pesqueira, marioribeiro@pesqueira.ifpe.edu.br

22 Doutora em Geociências, IFPE Campus Pesqueira, josineide@pesqueira.ifpe.edu.br 
e os solos tratados com $\mathrm{H}_{2} \mathrm{O}_{2} 30 \%$. A fração silte foi maior nos dois solos com MO. A fração argila $(<4 \mu \mathrm{m})$ no solo SB oxidado $\mathrm{H}_{2} \mathrm{O}_{2} 30 \%$ apresentou menor teor de argila do que o SB com MO, sugerindo que uma fração das partículas de argila está intimamente ligada a matéria orgânica do solo. Os valores dos limites de consistência do solo SB e SJ apresentaram-se mais altos no solo com MO. Porém, o valor de Plasticidade no solo com MO e sem a MO foi o mesmo para o solo SB. Pode-se inferir dessa forma, que a matéria orgânica afeta a distribuição granulométrica das frações finas e a plasticidade do solo com maior teor de matéria orgânica.

Palavras-Chave: solo, matéria orgânica, limite de plasticidade, limite de liquidez, granulometria.

\section{Introdução}

A caracterização do solo para os diferentes usos, como tráfego de máquinas ou construções, torna-se importante, pois, solos que apresentam alta porcentagem de partículas finas são muito influenciados pela umidade, causando grandes variações nas suas propriedades plásticas. Nessas circunstâncias é importante não apenas fazer uma análise granulométrica para caracterizá-lo, mas também, determinar o teor de matéria orgânica e a consistência desse solo. Essas propriedades estão interligadas, uma vez que o limite de plasticidade do solo pode ser elevado pelo aumento do teor de matéria orgânica, que também depende da quantidade e do tipo da argila presente (CAPUTO, 1994).

A matéria orgânica do solo (MOS) possui grande influência positiva no comportamento dos solos, nos aspectos físicos (densidade, porosidade), químicos (liberação e fixação de nutrientes) e biológicos (desenvolvimento de microorganismos). Suas características e valores dependem de fatores como temperatura, aeração, $\mathrm{pH}$ e disponibilidade de água e nutrientes, que são condicionados pelo uso e manejo dos solos (NASCIMENTO et al, 2010). Embora se encontre em quantidades reduzidas nos solos minerais $(<10 \%)$, tem papel fundamental na melhoria da fertilidade do solo e no aumento da produtividade vegetal. Influência também na formação de agregados, reduzindo a coesão do solo, o que gera uma maior permeabilidade do solo para o ar, e consequentemente uma maior oxigenação para a biota local (LUCHESE, FAVERO, LENZI, 2002).

Devido à importância do conhecimento das características do solo o objetivo deste 
trabalho foi avaliar a influência da matéria orgânica (MO) nos valores do limite de liquidez (LL) e plasticidade (LP) do solo, e na distribuição das frações granulométricas do mesmo a partir de uma análise comparativa entre dois métodos de determinação da matéria orgânica.

\section{Fundamentação Teórica}

A plasticidade ou consistência de um solo define a capacidade dos solos de serem moldados, sob certas condições de umidade, sem variação do volume sendo uma importante propriedade dos solos finos (argilas e siltes) (CAPUTO, 1994). O argilomineral presente no solo influencia os Limites de Atterberg, sendo mais fortemente o limite de liquidez e mais fracamente o limite de plasticidade, como se observa na Tabela 1.

Tabela 1: Limites de Atterberg de minerais de argila (argilomineral) Fonte: Modificado de Massad (2016) -

Apud Lambe e Whitman, (1969)

\begin{tabular}{l|c|c} 
Argilomineral & LL (\%) & LP (\%) \\
\hline Montmorilonita & $290-710$ & $54-81$ \\
Ilita & $95-120$ & $45-53$ \\
Caulinita & $38-59$ & $27-37$ \\
\hline
\end{tabular}

O Índice de Plasticidade (IP) é um indicador da plasticidade de um solo. Este índice é maior para solos argilosos e baixos para solos arenosos, pois, é condicionado pela presença de argilomineral e de sua ausência nas areias (FIORI; CARMIGNANI, 2001) e é determinado pela relação entre o Limite de Liquidez (LL) e Limite de Plasticidade (LP), conforme a equação:

$$
I P=L L-L P
$$

O Índice de Plasticidade também é influenciado pela matéria orgânica presente nos solos finos, porém, essa forma de influência não é unânime entre os autores. Fiori e Carmignani (2001) cita que a matéria orgânica incrementa o valor do limite de plasticidade sem elevar necessariamente o valor do limite de liquidez. Ribeiro et al (2004) cita que a matéria orgânica pode influenciar negativamente a plasticidade das argilas, promovendo a aderência e aumentando a coesão das partículas após secagem.

A matéria orgânica presente no solo tem sua importância, uma vez que o solo representa uma grande reserva de carbono orgânico, principalmente nas regiões como as de clima quente e úmido. Com o revolvimento do solo para plantio, ocorre uma rápida mineralização de resíduos vegetais e consequente mudança nos teores de matéria orgânica do solo (MOS), dessa forma, a distribuição das frações de matéria orgânica no solo pode ser utilizada como indicador da mudança de manejo do solo ou da qualidade ambiental do mesmo 
(LAL, 2004).

Além do papel de promover o bom funcionamento do solo, a matéria orgânica (MO) representa o terceiro maior reservatório de carbono terrestre. Porém, dependendo do manejo, pode ocorrer grande perda dessa matéria orgânica (40\%) em pouco tempo, em áreas de solo submetidas a agricultura convencional (TIESSEN et al., 1994)

\section{Metodologia}

Para quantificar a matéria orgânica dos solos e avaliar sua influência na distribuição das frações granulométricas do solo e no teste de liquidez e plasticidade, amostras de $300 \mathrm{~g}$ de dois solos com texturas diferentes (figura 01) foram coletados em dois pontos distintos do município de Pesqueira, Agreste de Pernambuco, os quais foram denominados de solo Juazeiro (SJ) e solo Barranco (SB). Após a coleta os solos foram colocados para secar ao ar livre e à sombra. Em seguida, foram destorroados e preparados de acordo com o exigido em norma da ABNT para cada ensaio. Todas as análises foram realizadas no laboratório de mecânica dos solos do IFPE - Campus Pesqueira.

- Determinação do teor de matéria Orgânica (MO) no solo

A determinação do teor da matéria orgânica no solo foi realizada segundo dois procedimentos: Método da Perda de Massa por Ignição (PMI) e Método por oxidação através da reação com peróxido de hidrogênio $\left(\mathrm{H}_{2} \mathrm{O}_{2}\right.$ a $\left.30 \%\right)$. Estes dois métodos foram validados por Miranda et al. (2015) em sedimentos estuarinos.

Para a determinação da MO pelo método da Perda de Massa por Ignição (PMI), pesouse $4 \mathrm{~g}$ do solo SJ e SB natural e também $4 \mathrm{~g}$ do solo SJ passado em peneira 0,42 mm (\#40), e calcinou-se em mufla a temperatura de $450^{\circ} \mathrm{C}$ por um período de $4 \mathrm{~h}$. Para a determinação da MO por oxidação com peróxido de Hidrogênio $\left(\mathrm{H}_{2} \mathrm{O}_{2}\right.$ a $30 \%$ v/v) $50 \mathrm{~g}$ de cada amostra foi pesada e em seguida adicionado $150 \mathrm{~mL}$ de $\mathrm{H}_{2} \mathrm{O}_{2}$ à $30 \% \mathrm{v} / \mathrm{v}$ por $96 \mathrm{~h}$ para reação total. Ao final, os sedimentos foram lavados com água destilada e secos em estufa a $60^{\circ} \mathrm{C}$, por $24 \mathrm{~h}$. Em ambos os métodos, o teor da MO foi determinado por gravimetria através da diferença de peso da amostra antes e depois da eliminação da matéria orgânica.

- Análise Granulométrica

A determinação granulométrica dos sedimentos foi feita baseada na metodologia adotada por Suguio (1973), na qual as frações maiores (grosseira) que 0,063mm foram separados com auxílio de peneiras, e a fração dos finos $(<0,063 \mathrm{~mm})$ foram separados através 
do método da pipetagem, baseado na lei de Stoken, que utiliza a velocidade terminal de sedimentação das partículas em meio aquoso.

- Ensaios do Limite de Liquidez e Plasticidade

O ensaio de limite de liquidez foi executado tomando-se $200 \mathrm{~g}$ de solo SJ e SB ambos naturais, destorroados, quarteados e passados na peneira 0,425 mm (\#40). Em seguida, essa massa foi colocada no aparelho de Casagrande e contou-se o número de golpes necessários para se fechar o sulco feito previamente nessa massa até o fechamento na parte central.

O ensaio de limite de plasticidade realizou-se fazendo rolar sobre um vidro esmerilhado uma porção da massa de solo até se transformar num cilindro de $10 \mathrm{~cm}$ de comprimento e $3 \mathrm{~mm}$ de diâmetro.

Realizaram-se também o ensaio de Limite de liquidez e de plasticidade nas amostras dos solos $\mathrm{SJ}$ e $\mathrm{SB}$, as quais foram oxidadas com peróxido de hidrogênio a 30\%, para eliminação da MO, a fim de comparação do resultado com a amostra natural.

\section{Resultados e Discussão}

- Determinação do teor de Matéria Orgânica (MO) nos solos

Os teores de matéria orgânica obtidos para os solos SJ e SB através do método PMI foram $7,2 \%$ e $1,5 \%$, respectivamente. As amostras submetidas ao peróxido de hidrogênio $\left(\mathrm{H}_{2} \mathrm{O}_{2}\right)$ a $30 \%$ apresentaram teor de MO 8,9\% para solo SJ e 3,2\% para solo SB (Figura 1). Para o solo SJ passado em peneira de $0,425 \mathrm{~mm}$ o teor de MO foi $9,9 \%$ no método PMI e $20,86 \%$ na oxidação do solo com $\mathrm{H}_{2} \mathrm{O}_{2}$ a $30 \%$.

Analisando os dois tratamentos aplicados, verificou-se que os teores de MO nos solos oxidados com $\mathrm{H}_{2} \mathrm{O}_{2}$ a $30 \%$ foram significativamente maiores do que nos solos calcinados. Estes resultados sugerem que o $\mathrm{H}_{2} \mathrm{O}_{2}$ a $30 \%$ oxidou além da $\mathrm{MO}$ lábil, que é mais reativa, a MO refratária, mais resistente à degradação. Quando se compara também o teor de MO no solo SJ peneirado, obtido pelos dois métodos, verifica-se valores maiores que o solo SJ natural, o que confirma que a matéria orgânica tem preferência de adsorção pelas frações granulométricas mais finas. 
Figura 1: Porcentagens de MO nos solos SJ e SB obtidas através dos métodos de PMI (calcinação) e oxidação com $\mathrm{H}^{2} \mathrm{O}^{2} 30 \%$. Fonte: Própria

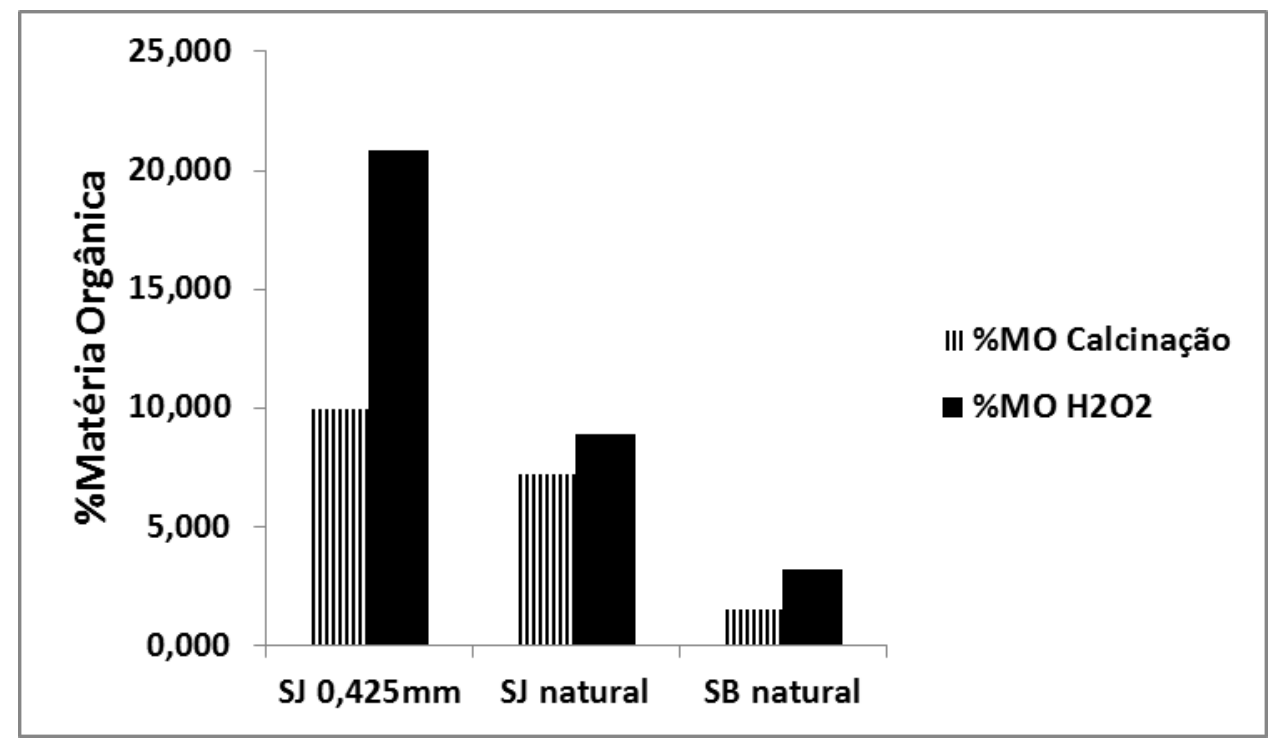

- Avaliação da Influência da Matéria Orgânica (MO) na análise granulométrica

Os resultados obtidos na análise granulométrica através do peneiramento seco (sedimentos grosseiros) dos solos SJ e SB com e sem a matéria orgânica podem ser visualizados na figura 2. Em ambos os solos, verifica-se que as frações granulométricas se distribuíram de forma semelhante independente do tratamento, indicando que a MO não influência a distribuição dos grãos nas diferentes frações de sedimentos grosseiros.

A porcentagem de finos nas amostras dos solos SJ e SB sem eliminação da matéria orgânica foi de 42,8\% e 40,1\%, respectivamente. Para os solos oxidados por $\mathrm{H}_{2} \mathrm{O}_{2}$ preliminarmente, a porcentagem de finos foi $36,9 \%$ para o solo SJ e 34,9\% para o solo SB e os resultados, obtidos através da técnica da pipetagem podem ser observados na Figura 3.

Figura 2: Porcentagens das frações granulométricas grosseiras $(>0,063 \mathrm{~mm})$ nos solos SJ e SB com e sem matéria orgânica. Fonte: Própria

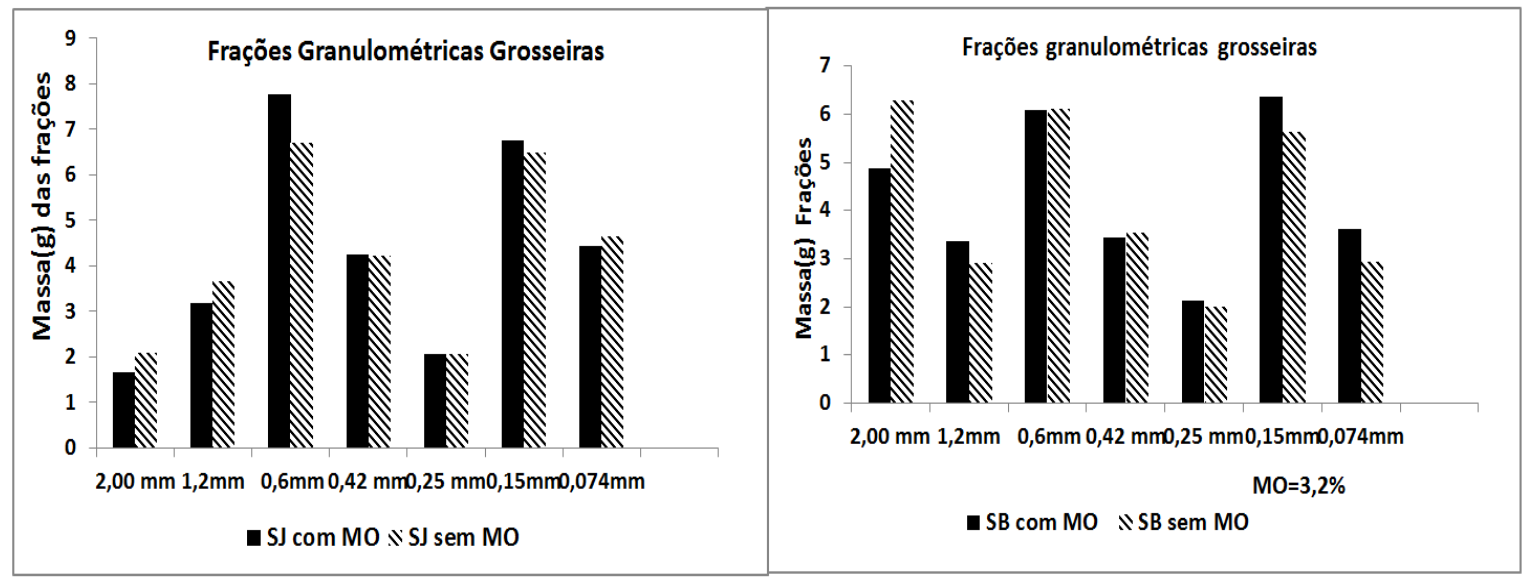


Figura 3: Porcentagem das frações granulométricas finas $(<0,063 \mathrm{~mm})$ nos solos $\mathrm{SJ}$ e $\mathrm{SB}$ com MO e sem a MO . Fonte: própria

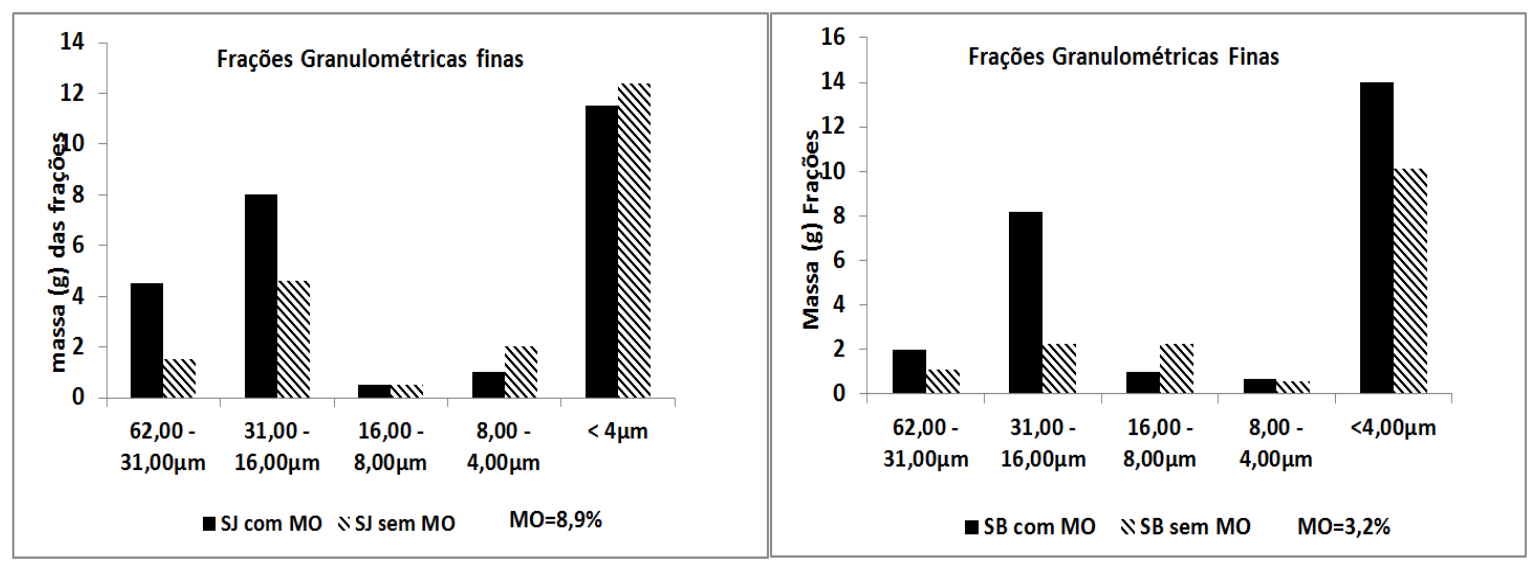

Diferentemente do observado para a fração grosseira, verificou-se uma diferença na distribuição das frações finas entre o controle (com MO) e os solos tratados com $\mathrm{H}_{2} \mathrm{O}_{2} 30 \%$ para os dois solos. A fração silte muito grosso a grosso $(62,00 \mu \mathrm{m}$ a $16 \mu \mathrm{m})$ foi maior nos dois solos com MO.

A fração argila $(<4 \mu \mathrm{m})$ do solo SB oxidado $\mathrm{H}_{2} \mathrm{O}_{2} 30 \%$ (sem MO) apresentou menor teor de argila do que o SB com material orgânica (controle), o que indica que uma fração das partículas de argila está intimamente ligada às substâncias húmicas (material orgânica) do solo. Este comportamento é coerente com o que cita Goldberg et al., (2000) que, em uma condição definida de solo, o teor da matéria orgânica é diretamente proporcional ao teor da argila, mostrando alta afinidade química da carga negativa da matéria orgânica com a carga positiva da argila.

- Limite de Liquidez e Plasticidade

Verifica-se que os valores dos limites de consistência do solo SB apresentaram valores mais altos que o solo SJ (Tabela 2). Possivelmente, isto ocorre devido a maior quantidade de fração argila no solo SB, como foi observado nos dados da análise granulométrica.

Tabela 2: Resultados dos ensaios de Limite de Liquidez (LL), de Plasticidade (LP) e Índice de Plasticidade (IP) nos solos SJ e SB.

\begin{tabular}{l|c|c|c}
\hline Solo & LL (\%) & LP (\%) & IP (\%) \\
\hline SJ natural (com matéria orgânica) & 18 & 8 & 10 \\
SJ sem matéria orgânica & 17 & 6 & 11 \\
SB natural (com material orgânica) & 34 & 15 & 19 \\
SB sem material orgânica & 32 & 13 & 19 \\
\hline
\end{tabular}


Os resultados de LL, LP e IP no solo SJ mostraram pequena diferença nos limites de consistência quando se compara o solo natural (controle) e o solo sem matéria orgânica (Figura 4).

Embora os solos com matéria orgânica e sem matéria orgânica apresentaram diferença de valores para LL, LP e IP a classificação dos solos não foi alterada, sendo o solo SJ classificado como arenoso (IP < 10 e LL < 30) e o solo SB classificado como siltoso $(5<$ IP < 25 e $20<$ LL < 50) (CRAterre, 1979)

Figura 4: Valores dos Limites de Consistência (LL, LP, IP) nos solos SJ e SB com e sem matéria orgânica. Fonte: Própria

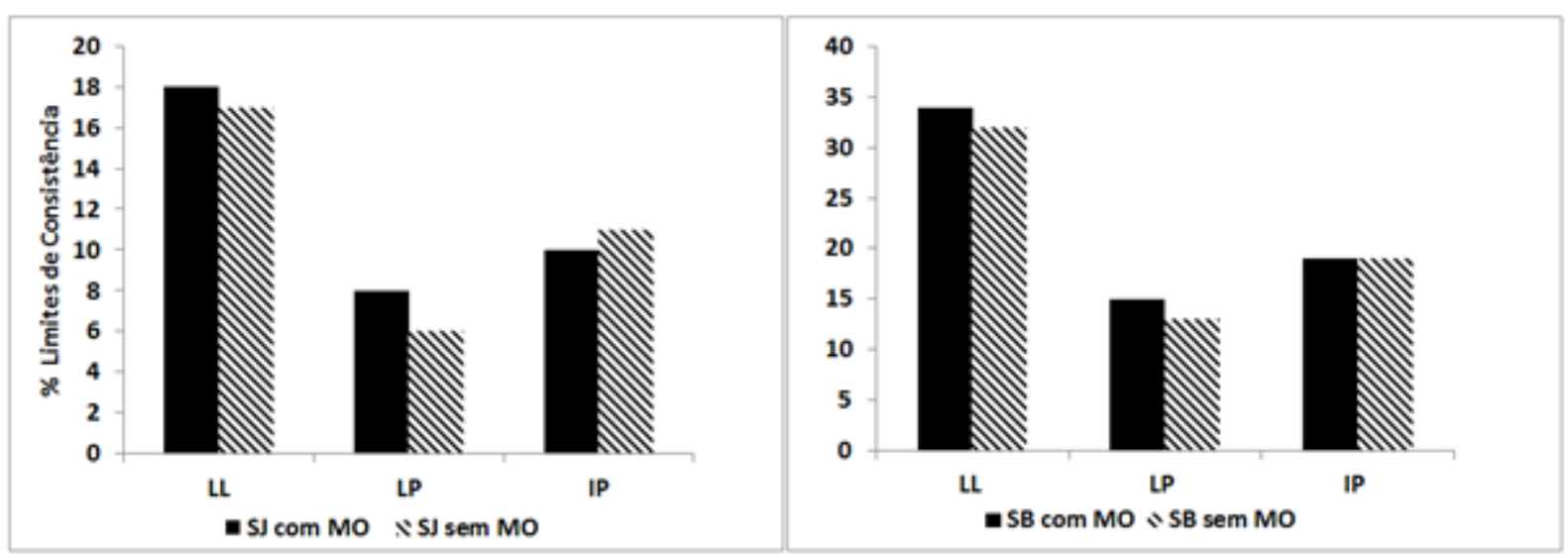

O Limite de Plasticidade (LP) e Limite de Liquidez (LL) do solo SJ apresentou-se maior no solo com matéria orgânica (33,3 e 5,6\% respectivamente).Porém, o valor do Índice de Plasticidade (IP) no solo SJ mostrou-se um pouco menor $(9,1 \%)$, no solo natural, com matéria orgânica, confirmando o que a maioria dos autores assume, que a matéria orgânica incrementa a plasticidade. Este incremento na plasticidade pode ser explicado pela maior porcentagem de matéria orgânica $(8,9 \%)$ neste solo. Resultados semelhantes foram encontrados por Fiori e Camignani (2001)

Para o solo SB, os limites de consistência apresentaram valores maiores para o LL $(6,2 \%)$ e LP (23\%) para o solo com matéria orgânica. Porém, obteve-se o mesmo valor de Plasticidade (IP) no solo com MO e sem a MO. Pode-se inferir dessa forma, que a matéria orgânica não parece afetar a plasticidade do solo SB, ou sua influência é muito pequena que não é notada. Conclusões semelhantes foram observados por Ribeiro et al., (2004). Uma justificativa para este fato é a quantidade reduzida de matéria orgânica neste solo. 


\section{Conclusões}

A matéria orgânica presente nos solos influencia a distribuição granulométrica nas diferentes frações, especialmente nos solos ricos em frações mais finas, como silte e argila, mascarando o resultado do teor das partículas finas;

A presença de matéria orgânica nos solos influenciou mais fortemente o Limite de Plasticidade do que o Limite de Liquidez;

O maior teor de matéria orgânica nos solos pode aumentar o índice de plasticidade do mesmo.

\section{Referências}

CAPUTO, H. P. Mecânica dos solos e suas aplicações. 6 ed. Rio de Janeiro: LTC Editora S.A, 1994, 225p.

CRATerre - Centre Internacional de la Construction en Terre. Construire en terre. Paris: CRATerre. 1979. $270 \mathrm{p}$

FIORI, A. P.; CAMIGNANI, L. Fundamento de mecânica dos solos e das rochas: aplicações na estabilidade de taludes, Editora UFPE, 2001.

GOLDBERG, S.; LEBRON, I.; SUAREZ, D. L. Soil colloidal behavior. In: Summer, M. E. Handbook of soil science. New York: CRC Press, 2000. Cap. 6, p. B195-B240.

LAL, R. Agricultural activities and the global carbono cycle. Nutrient Cycling in Agroecoystems, v.70,n.2,p.103-116,2004

LUCHESE, E. B., FAVERO, L. O. B., LENZI, E. Fundamentos da Química do Solo. Rio de Janeiro: Freitas Bastos, 2002.159p.

MASSAD, F. Mecânica dos solos experimental, Editora Oficina de Textos, 2016.288p.

NASCIMENTO, P. C. et al. Teores e características da matéria orgânica de solos hidromórficos do Espírito Santo. R. Bras. Ci. Solo, v.34. n.2, p.339-348, 2010.

RIBEIRO, C.G. Estudo sobre a Influência da Matéria Orgânica na Plasticidade e no Comportamento Térmico de uma Argila. Cerâmica Industrial, v.9 n.3, p 1-4. 2004.

SUGUIO, K., 1973. Introdução a sedimentologia. São Paulo. Ed. Edgard Blücher. EDUSP, $317 \mathrm{p}$.

TIESSEN, H., CUERVAS, E., CHACON, P. The role of soil organic matter in sustaining soli fertility.Nature.v.371,p.783-784,1994 